\title{
Competence of Secondary School Teachers' Usage of Bloom's Taxonomy of Education on Lesson Preparation, Presentation and Students' Assessments in Science
}

\author{
Ajayi, Lois Folasayo \\ Department of Science Education, Faculty of Education Ekiti State University, Ado-Ekiti, Nigeria
}

\begin{abstract}
The study examined the competence of secondary school teachers' usage of Bloom's taxonomy of educational objectives on lesson preparation, presentation and students' assessments in Science. The study adopted a descriptive research design of survey type. 60 Science teachers were used for this study. Stratified random sampling technique was used in selecting the 60 teachers. A 15-item inventory was administered on the 60 teachers and the data collected was analysed using descriptive statistics. The outcome of the analysis revealed that teachers' lesson preparation, presentation and students' assessment test were not in conformity with the Bloom's taxonomy of education.
\end{abstract}

Keywords: Blooms' taxonomy, Competence, Secondary school, Teachers, Lesson preparation, Lesson presentation, Students assessments, Science.

\section{INTRODUCTION}

$\mathrm{T}$ he success of teaching begins with lesson preparation. A well-prepared lesson is likely to yield a huge success in students' participation and performance in both internal and external examinations at Senior Secondary School (SSS) level (Eurydice-Maria and Maria, 2018). Lesson plans are wellprepared step by step teachers' and students' activities deliberately put together in order to achieve some educational objectives. Learning objectives are stated expectations from the learners as a result of the classroom activities exposed to. They are carefully constructed to bring about some specific learning outcomes. Appropriate learning objectives are expected to clearly indicate all necessary verbs that will lead to the stated learning objectives. Steps to be taken in the presentation of the learning activities must also conform with the verbs itemised in the learning objectives. These will make the classroom interaction meaningful and productive. To this end, lesson plans are not expected to be prepared for the purpose of meeting the school principal's or education inspector's requirements but are planned in order to ensure that the most thoughtful approaches are used with the aim of getting the student to where the learning objectives planned them to be (Brophy, 2001; Creswell, 2018). The focus of a good teacher while writing the lesson plan should be to ensure that his students actually accomplish the stated learning objectives (Sofos and Darra, 2015). Regardless of any standard laid by the school or education authorities, every effective lesson plan should build towards the achievement of the stated learning objectives and connect long-term instructional goals. (Giannakidou, Yoftsali and Tziora, 2013). A good lesson plan in Science focuses on "hands-on" strategies where the teaching processes lead the students to activities in Science and manipulation of learning materials. A well-planned lesson should be able to answer the following questions:
a. What do I want students to learn?
b. What teaching and learning activities should be used to accomplish the question?
c. How will I ensure students understood what they learnt?

To obtain the right responses to the questions, the teacher's lesson plan according to Brophy (2001) must:
a. Communicate to students WHAT they are to learn
b. Communicate to students WHY it is essential to learn the materials and acquire the learning experiences provided
c. Communicate to students HOW what is being learned is related to their previous knowledge.
d. Communicate to students HOW the learning will occur.

A teacher's lesson plan that would result in a complete and perfect learning outcome is expected to be guided by Bloom's taxonomy of educational objectives. Bloom's Taxonomy of educational objectives presented six levels that must be considered on effective lesson preparation and presentation. Although there was no specified proportion of each level of Bloom's taxonomy of educational objective level neither there was an emphasis on equity but every Bloom's cognitive taxonomy levels are expected to be captured in good lesson delivery and students' assessment. Appropriate consideration of all the six levels in lesson presentation and students' assessment is capable of producing well trained and educated person. The learning outcomes will be the type that fulfils the nation's educational objectives and produce a self-reliant citizen. 
Bloom's taxonomy was created by a group of psychologists in 1956, led by Benjamin Bloom. The taxonomy comprised of six levels and could be expressed diagrammatically showing the classification of different levels of learning. The six levels in order (lowest to highest), according to Bloom (1956) are knowledge, comprehension, application, analysis, synthesis and evaluation. All these six levels formed the cognitive domain which teachers can apply to enhance intellectual learning in the typical classroom environment. The six levels and their corresponding verbs according to Bloom (1956) relate to how student's brain processes information and thoughts. The levels and their corresponding verbs are shown in table 1.

Table 1: Bloom's taxonomy levels and their corresponding verbs

\begin{tabular}{|c|c|}
\hline Level & Verbs \\
\hline $\begin{array}{c}\text { Knowledge: which is at the } \\
\text { bottom level, is the ability to } \\
\text { recognize and recall specific } \\
\text { items and facts. }\end{array}$ & $\begin{array}{c}\text { define, repeat, record, list, recall, name, } \\
\text { relate and underline }\end{array}$ \\
\hline $\begin{array}{c}\text { Comprehension: Understanding } \\
\text { of facts and ideas to make } \\
\text { comparisons by determining the } \\
\text { similarities and differences. }\end{array}$ & $\begin{array}{c}\text { translate, restate, discuss, describe, } \\
\text { recognize, explain, express, identify, } \\
\text { locate, report, review and tell. }\end{array}$ \\
\hline $\begin{array}{c}\text { Application: Take information of } \\
\text { an abstract nature and use it in } \\
\text { concrete and new situations. }\end{array}$ & $\begin{array}{c}\text { interpret, apply, employ, use, } \\
\text { demonstrate, dramatize, practice, } \\
\text { illustrate, operate, schedule, shop and } \\
\text { sketch. }\end{array}$ \\
\hline $\begin{array}{c}\text { Analysis: can break down into its } \\
\text { constituent parts, revealing the } \\
\text { relationships among them. }\end{array}$ & $\begin{array}{c}\text { Distinguish, analyze, differentiate, } \\
\text { appraise, calculate, experiment, test, } \\
\text { compare, contrast, criticize, diagram, } \\
\text { inspect, debate, inventory, question, } \\
\text { relate, solve, examine, categorize }\end{array}$ \\
\hline $\begin{array}{c}\text { Synthesis: is pulling together } \\
\text { disorganized elements or objects } \\
\text { to form a whole. }\end{array}$ & $\begin{array}{c}\text { Compose, plan, propose, design, } \\
\text { formulate, arrange, assemble, collect, } \\
\text { construct, create, set up, organize, } \\
\text { manage, prepare }\end{array}$ \\
\hline $\begin{array}{c}\text { Evaluation: to be able to make } \\
\text { judgements about the value of } \\
\text { materials and methods. }\end{array}$ & $\begin{array}{c}\text { Judge, appraise, evaluate, rate, compare, } \\
\text { value, revise, score, select, choose, } \\
\text { assess, estimate, measure }\end{array}$ \\
\hline
\end{tabular}

Evaluation
- Synthesis
- Analysis
- Application
- Comprehension
- Knowledge

Figure 1: Simplified Bloom's Taxonomy of learning

The simplified version of the taxonomy modifying the original domain to form new domain as shown in figure 1 was developed by Lorin Anderson, a former student of Bloom, and David Krathwohl in the mid-nineties (Anderson, Krathwohl, Airasian, Cruikshank, Mayer, Pintrich, and Raths, 2001)
Corresponding verbs under each level of the simplified version of Bloom's taxonomy according to Anderson and Krathwohl (2001) are as shown in table 2

Table 2: Simplified Bloom's taxonomy levels and their corresponding verbs

\begin{tabular}{|c|c|}
\hline Level & Verbs \\
\hline $\begin{array}{l}\text { Remembering: Recall or retrieve } \\
\text { previous learned information. }\end{array}$ & $\begin{array}{l}\text { defines, describes, identifies, knows, } \\
\text { labels, lists, matches, names, outlines, } \\
\text { recalls, recognizes, reproduces, selects, } \\
\text { states }\end{array}$ \\
\hline $\begin{array}{l}\text { Understanding: Comprehending } \\
\text { the meaning, translation, } \\
\text { interpolation, and interpretation } \\
\text { of instructions and problems. } \\
\text { State a problem in one's own } \\
\text { words. } \\
\end{array}$ & $\begin{array}{l}\text { comprehends, converts, defends, } \\
\text { distinguishes, estimates, explains, } \\
\text { extends, generalizes, gives an example, } \\
\text { infers, interprets, paraphrases, predicts, } \\
\text { rewrites, summarizes, translates }\end{array}$ \\
\hline $\begin{array}{l}\text { Applying: Use a concept in a } \\
\text { new situation or unprompted use } \\
\text { of an abstraction. Applies what } \\
\text { was learned in the classroom } \\
\text { into novel situations in the work } \\
\text { place. }\end{array}$ & $\begin{array}{l}\text { applies, changes, computes, constructs, } \\
\text { demonstrates, discovers, manipulates, } \\
\text { modifies, operates, predicts, prepares, } \\
\text { produces, relates, shows, solves, uses }\end{array}$ \\
\hline $\begin{array}{l}\text { Analyzing: Separates material or } \\
\text { concepts into component parts so } \\
\text { that its organizational structure } \\
\text { may be understood. } \\
\text { Distinguishes between facts and } \\
\text { inferences. }\end{array}$ & $\begin{array}{l}\text { analyzes, breaks down, compares, } \\
\text { contrasts, diagrams, deconstructs, } \\
\text { differentiates, discriminates, } \\
\text { distinguishes, identifies, illustrates, } \\
\text { infers, outlines, relates, selects, separates }\end{array}$ \\
\hline $\begin{array}{l}\text { Evaluating: Make judgments } \\
\text { about the value of ideas or } \\
\text { materials. }\end{array}$ & $\begin{array}{c}\text { appraises, compares, concludes, } \\
\text { contrasts, criticizes, critiques, defends, } \\
\text { describes, discriminates, evaluates, } \\
\text { explains, interprets, justifies, relates, } \\
\text { summarizes, supports }\end{array}$ \\
\hline $\begin{array}{l}\text { Creating: Builds a structure or } \\
\text { pattern from diverse elements. } \\
\text { Put parts together to form a } \\
\text { whole, with emphasis on } \\
\text { creating a new meaning or } \\
\text { structure. }\end{array}$ & $\begin{array}{l}\text { categorizes, combines, compiles, } \\
\text { composes, creates, devises, designs, } \\
\text { explains, generates, modifies, organizes, } \\
\text { plans, rearranges, reconstructs, relates, } \\
\text { reorganizes, revises, rewrites, } \\
\text { summarizes, tells, writes }\end{array}$ \\
\hline
\end{tabular}

An effective teacher must be able to incorporate all the verbs under each level of the taxonomy in his lesson plan and apply them in his teaching activities. A lesson presented across the six levels is expected to produce a perfect learning outcome (Riazi, 2010; Rupani, 2011; Kolb, 2014; Irfan and Shelina, 2016). In an excellent lesson delivery, learners are expected to be well equipped to replicate what was learned in the classroom in real-life situations. In Nigeria, there are three terms in an academic session and a term runs for 14 weeks. Out of the 14 weeks, ten weeks are assigned to consistent classroom activities while two weeks are dedicated to students' assessment through what is called 'terminal examination. Terminal examinations are constructed and conducted by the subject teachers. They are teacher-made examinations.

After the discharge of each lesson, students are expected to be assessed by the teacher. Test items preparation for such assessment of students is supposed to incorporate the verbs under the six levels of Bloom's Taxonomy in a normal proportion as reflected in the lesson plan used in teaching the students.

It was observed that several teachers in Nigeria classrooms are not considering the use of Bloom's Taxonomy 
of educational objectives as expected both in their lesson plan and students' assessment items. Knowledge and use of Bloom's taxonomy might be determined, to some extent, by the teacher's qualification and experience. To be qualified to teach Science in Nigeria secondary schools, the teacher must possess a minimum of a University degree in Education. Degree holders outside education disciplines are not qualified to be a teacher in secondary schools. To be experienced in the teaching profession, one must have spent not less than three years of continuous teaching. Qualifications and experiences of secondary school teachers might have a significant influence on the knowledge and use of Bloom's cognitive taxonomy of educational objectives. The study was out to investigate and cross-examine the lesson plan of secondary school teachers as well as their students' assessment items to determine the extent of compliance with Bloom's taxonomy of educational objectives.

\section{Statement of the Problem}

There are several school leavers in Nigeria that are not productive despite the level of educational acquisition. A lot of them are finding it difficult to apply what they learned in school to improve society and create their livelihood. If the learning outcomes are weak, there is a likelihood that the learning process was weak, and the objectives of learning lacked focus or wrongly stated. Applying Bloom's Taxonomy of educational objectives presented action verbs for teaching and assessment of learners that can produce the expected learning outcomes.

As good as the taxonomy is in ensuring a productive learning system and outcomes, teacher's qualifications and experience in the teaching job are the major determinants in the effective use of it. Teachers' knowledge and use of taxonomy are also essential in achieving the proposed learning outcomes. In light of the stated facts, this study was designed to investigate the extent to which the teachers in Nigerian secondary schools utilize Bloom's taxonomy in their teaching-learning process and assessment of their learners.

\section{Research Questions}

The following research questions were raised to guide the study:

1. What is the status of Science teachers in Senior Secondary Schools in Nigeria?

2. What is the percentage of Science teachers with adequate knowledge of Bloom's taxonomy of Education?

3. What percentage of Science teachers apply the Bloom's taxonomy in their lesson preparation and presentation?

4. What is the percentage of Science teachers applying the Bloom's taxonomy in students' assessment?

5. What is the percentage distribution of students' activities and skills in Science across Bloom's taxonomy?

\section{METHODOLOGY}

The study adopted a descriptive research design of survey type. The sample for the study consisted of 60 Science teachers and 300 students selected from four states out of the six states in South-West, Nigeria. A simple random sampling technique was used to select the four states. Five schools from each of the four states were thereafter selected giving a total of 20 schools for the study. A stratified random sampling technique was used to select one teacher each and five students for Biology, Chemistry, and Physics subjects from the 20 schools sampled. Secondary school final year (normally referred to as Senior Secondary School three in Nigeria) syllabuses, the teachers that implemented them and the students taught by the teachers were used for the study. Two instruments were used in this study: The first instrument was a 15-item self-constructed inventory of three sections titled Inventory on Teachers' Usage of Bloom's Taxonomy (ITUBT). Section A having three items was on demographic variables, Section B having six items was on teachers' lesson preparation while Section $\mathrm{C}$ with six items focused on teacher-made assessment test items. The second instrument was also an inventory on Students' Learning Activities and Skills in Science (ISLASS). This second instrument comprised 18 items in three sections. Section A has 6 items which focused on activities and Science skills carried out by the students in Biology as recorded in their lesson notes. Section B comprised 6 items on Chemistry activities and skills while section $\mathrm{C}$ also having 6 items focused on activities and skills in Physics. Face and content validity of the two instruments were ensured and the reliability of the instruments were carried out by administering the two instruments on 9 teachers and 30 students outside the sample. The data generated from the 9 teachers and 30 students were subjected to Pearson's Product Moment Correlation and reliability coefficients of 0.87 for ITUBT and 0.82 for ISLASS were obtained at 0.05 level of significance. The researcher personally took the instruments to each of the schools and administered it on the 60 sampled teachers and 300 students in Biology, Chemistry and Physics. At each school, the researcher haven obtained the necessary permissions demanded the Senior Secondary School III (SSS III) second term examination questions in Biology, Chemistry, and Physics, lesson plan, scheme of work used by the teachers for 10 weeks, the teachers that handled the subjects and students' activities notes. Under normal circumstances, ten weeks are designed for teaching out of the thirteen weeks in a term. ITUBT was used to take inventory of the teachers' lesson preparations and presentations through the lesson plans, the scheme of work, as used by the teachers, to determine the compliance of the class activities with the six levels of Bloom's taxonomy of educational objectives. Students' personal activity and skill acquisition notes were also collated and subjected to ISLASS. Test items in the second term teacher-made examinations were also subjected to inventory taking using ITUBT. The second term's work was preferred in this study being the last and final sessional term preceding the external examination for Senior Secondary Schools in 
Nigeria. Teachers' demographic variables were also obtained accordingly. Data collected through the inventory across the 60 teachers and 300 students sampled were analyzed using descriptive statistics to determine the level of compliance with Bloom's taxonomy of educational objectives both in the lesson preparation, presentation, and students' assessment.

\section{RESULTS}

Question 1 What is the status of Science teachers in Senior Secondary Schools in Nigeria?

Table 3: Percentage analysis of Science teachers' statuses in Senior Secondary Schools in Nigeria

\begin{tabular}{|c|c|c|}
\hline STATUS & $\mathrm{N}$ & $\%$ \\
\hline Qualified & 58 & 96.7 \\
Not qualified & 2 & 3.3 \\
Total & 60 & 100.0 \\
\hline Experienced & 55 & 91.7 \\
Not experienced & 5 & 8.3 \\
Total & 60 & 100.0 \\
\hline
\end{tabular}

Table 3 showed that $96.7 \%$ of the teachers sampled were qualified to teach the subjects at secondary school levels while only $3.3 \%$ were not qualified as teachers. The high percentage indicated that Nigerian teachers are qualified for the teaching job appointed them to do.

Question 2: What is the percentage of Science teachers with adequate knowledge of Bloom's taxonomy of Education?

Table 4: Percentage analysis of Science teachers with adequate Knowledge of Bloom's taxonomy

\begin{tabular}{|c|c|c|c|}
\hline Category & FK & PK & NK \\
\hline Knowledge & $60(100.0)$ & $0(0.0)$ & $0(0.0)$ \\
Comprehension & $59(98.3)$ & $1(1.7)$ & $0(0.0)$ \\
Application & $60(100.0)$ & $0(0.0)$ & $0(0.0)$ \\
Analysis & $59(98.3)$ & $1(1.7)$ & $0(0.0)$ \\
Synthesis & $56(93.3)$ & $3(5.0)$ & $1(1.7)$ \\
Evaluation & $57(95.0)$ & $3(5.0)$ & $0(0.0)$ \\
Average & $58.5(97.5)$ & $1.3(2.2)$ & $0.2(0.3)$ \\
\hline
\end{tabular}

Key:

FK - Full Knowledge

PK - Partial Knowledge

NK - No Knowledge

From table 4, it was revealed that on average, 97.5\% of the teachers sampled have full knowledge of the Bloom's taxonomy of educational objectives while $2.2 \%$ have partial knowledge and $0.3 \%$ have no knowledge at all. By implication, Nigerian Senior Secondary School teachers have adequate knowledge of Bloom's taxonomy of educational objectives

Question 3: What percentage of Science teachers apply the Bloom's taxonomy in their lesson preparation and presentation?
Table 5: Percentage analysis of Science teachers apply the Bloom's taxonomy in their lesson preparation and presentation?

\begin{tabular}{|c|c|c|c|}
\hline Category & $\mathrm{N}$ & $\%$ & Ranking \\
\hline Knowledge & 60 & 100.0 & $1^{\text {st }}$ \\
Comprehension & 24 & 40.0 & $2^{\text {nd }}$ \\
Application & 14 & 23.3 & $5^{\text {th }}$ \\
Analysis & 16 & 26.7 & $4^{\text {th }}$ \\
Synthesis & 11 & 18.3 & $6^{\text {th }}$ \\
Evaluation & 22 & 36.7 & $3^{\text {rd }}$ \\
\hline
\end{tabular}

Table 5 showed that $100.0 \%$ of the teachers sampled applied the 'knowledge' verbs under Bloom's cognitive taxonomy of educational objectives fully in their lesson preparation and presentation, $40.0 \%$ applied 'comprehension' verbs in addition to 'knowledge', 23.3\% incorporated 'application' to their presentations while $26.7 \%$ applied 'analysis'. The table further showed that only $18.3 \%$ incorporated 'synthesis' and $36.7 \%$ gave 'evaluation' some considerations. From the table, it showed that every teacher focused fully on 'knowledge' as it tops the rank. This was followed by 'comprehension', $3^{\text {rd }}$ in the rank was 'evaluation', $4^{\text {th }}$ was 'analysis', $5^{\text {th }}$ was 'application' while the least given attention by the teachers was 'synthesis' which was $6^{\text {th }}$ in the rank.

Question 4: What is the percentage of Science teachers applying the Bloom's taxonomy in students' assessment?

Table 6: Percentage analysis of Science teachers applying the Bloom's taxonomy in students' assessment

\begin{tabular}{|c|c|c|c|}
\hline Category & $\mathrm{N}$ & $\%$ & Ranking \\
\hline Knowledge & 60 & 100.0 & $1^{\text {st }}$ \\
Comprehension & 16 & 26.7 & $2^{\text {nd }}$ \\
Application & 9 & 15.0 & $4^{\text {th }}$ \\
Analysis & 12 & 20.0 & $3^{\text {rd }}$ \\
Synthesis & 7 & 11.7 & $6^{\text {th }}$ \\
Evaluation & 8 & 13.3 & $5^{\text {th }}$ \\
\hline
\end{tabular}

Table 6 showed that $100.0 \%$ of the teachers sampled applied the 'knowledge' verbs under Bloom's cognitive taxonomy of educational objectives fully in students' assessments, 26.7\% applied 'comprehension' verbs in addition to 'knowledge', $15.0 \%$ incorporated 'application' to the students' assessments while $20.0 \%$ applied 'analysis' in the test items. The table further showed that only $11.7 \%$ incorporated 'synthesis' and $13.3 \%$ gave 'evaluation' some considerations in students' assessment. From the table, it showed that every teacher focused fully on 'knowledge' aspect of the Bloom's taxonomy as it tops the rank followed by 'comprehension', $3^{\text {rd }}$ in the rank was 'analysis', $4^{\text {th }}$ was 'application', $5^{\text {th }}$ was 'evaluation' while the least given attention by the teachers was 'synthesis' which was $6^{\text {th }}$ in the rank.

Question 5: What is the percentage distribution of students' activities and skills in Science across Bloom's taxonomy? 
Table 7: Percentage analysis of the distribution of students' activities and skills in Science across Bloom's taxonomy?

\begin{tabular}{|c|c|c|c|}
\hline Category & $N$ & $\%$ & Ranking \\
\hline Knowledge & 300 & 100.0 & $1^{\text {st }}$ \\
Comprehension & 113 & 37.7 & $2^{\text {nd }}$ \\
Application & 68 & 22.7 & $4^{\text {th }}$ \\
Analysis & 92 & 30.7 & $3^{\text {rd }}$ \\
Synthesis & 48 & 16.0 & $5^{\text {th }}$ \\
Evaluation & 30 & 10.0 & $6^{\text {th }}$ \\
\hline
\end{tabular}

Table 7 revealed that $100.0 \%$ of the students sampled performed Science activities and acquired relevant skills in 'knowledge' verbs under Bloom's cognitive taxonomy of educational objectives. $37.7 \%$ could perform tasks in 'comprehension' verbs, $22.7 \%$ acquired skills in 'application' while $30.7 \%$ could perform tasks in 'analysis' related activities. The table further showed that only $16.0 \%$ acquired 'synthesis' skills in Science and $10.0 \%$ could carry out 'evaluation' skills in Science. From the table, it showed that all the student could perform tasks relating to 'knowledge' aspect of the Bloom's taxonomy as it tops the rank followed by 'comprehension'. $3^{\text {rd }}$ in the rank was 'analysis', $4^{\text {th }}$ was 'application', $5^{\text {th }}$ was 'synthesis' while the least in Science skills acquisition among students in Biology, Chemistry and Physics was 'evaluation' which was $6^{\text {th }}$ in the rank.

\section{DISCUSSION}

The findings of the study revealed that teachers in Nigeria Senior Secondary Schools were qualified to teach their subjects. Every teacher sampled in this study were University graduates in their respective disciplines. It showed further that the teachers have enough teaching experience required to teach the level of students assigned to them.

The findings of the study revealed further that teachers in Nigerian Senior Secondary School teachers have adequate knowledge of Bloom's taxonomy of educational objectives. They are, therefore, expected to be able to fully apply Bloom's cognitive taxonomy of educational objectives in their lesson preparation and delivery.

The findings of the study also showed that the teachers were deficient in the application of Bloom's cognitive taxonomy of educational objectives both in their lesson preparation and presentation. It was discovered that all the teachers used in the study fully concentrated in the 'knowledge' part of the taxonomy and partially considered 'comprehension' verbs in their lesson deliveries. Other levels of Bloom's cognitive taxonomy were virtually neglected despite the level of understanding of the teachers on what the taxonomy entails. This shows that students produced by these teachers might not be so productive and skillfully upright. The finding was in agreement with the works of Rupani (2011), Kolb (2014) as well as Irfan and Shelina (2016) who all agreed that lesson delivered without appropriate incorporation of Bloom's taxonomy of educational objectives will make learning difficult and unproductive. This finding was not in consonant with the assertion of Riazi and Mosalanejad (2010) who emphasized that the intent of using Bloom's taxonomy was to ensure that learning outcomes were designed in such a manner that enabled the teachers to gradually bring learners from acquiring subject information to its practical application in the real context and ultimately, create meaningful of their own from the same information.

The findings further showed that teachers in Nigeria though found qualified professionally, were not applying Bloom's cognitive taxonomy of educational objectives in the construction of the items used in assessing students' learning outcomes. Most of them only considered the 'knowledge' level of Bloom's cognitive taxonomy in assessing the learners' learning outcomes. Other levels were virtually neglected in the design of the test items. This implies that the assessments carried out by the teachers were deficient in producing perfect learning outcomes. This finding was in agreement with the findings of Riazi (2010), Rupani (2011), Kolb (2014), Irfan and Shelina (2016), and as well as Mwakamele (2017) who all agreed that teachers that neglect the use of Bloom's taxonomy in their students' assessments are not having right perspectives towards teaching. Thes shortcomings in the appropriate use of Bloom's taxonomy by Science teachers reflected in the types of activities and skills acquired by their students. Students were good mainly in 'knowledge' verbs of the taxonomy while they were observed so weak in the other Bloom's taxonomy levels and verbs $\mathrm{w}$

\section{CONCLUSION AND RECOMMENDATIONS}

The study was able to assess the competence of secondary school Science teachers in the use of Bloom's cognitive taxonomy of educational objectives in lesson preparation, presentation, and students' assessment. It was concluded that most Science teachers though qualified professionally and have adequate knowledge of Bloom's taxonomy, do not apply the taxonomy of educational objectives on their lesson preparation, presentation, and students' assessment. They only know but could not apply it appropriately. Most of them emphasize the 'knowledge' level of the taxonomy and this could jeopardize the perfect production of expected learning outcomes. Appropriate planning of lesson studies and the implementation that was expected to enhance the active roles of the teacher and students and contribute to the improvement of the education process and learning outcomes were neglected by the teachers. Based on the findings, it was recommended that all teachers should endeavor to incorporate the use of Bloom's cognitive taxonomy of educational objectives appropriately in their lesson preparation and presentation to necessitate free expression of students, enable them to contribute to the improvement of the education process, and obtain better learning outcomes. Teachers should also incorporate Bloom's taxonomy into students' assessments. This would reflect a true and clearer view of the learning objectives acquired by learners and their competence in applying the learned concepts in a real-life situation. 


\section{REFERENCES}

[1] Anderson, L. W., Krathwohl, D. R, Airasian, P. W., Cruikshank, K. A., Mayer, R. F., Pintrich, P. R., \& Raths, J. (2001). A Taxonomy for Learning, Teaching, and Assessing: A revision of Bloom's Taxonomy of Educational Objectives. New York: Pearson, Allyn \& Bacon.

[2] Anderson, L.W., \& Krathwohl, D. R. (2001). A taxonomy of learning, teaching and assessing. Abridged Edition. Boston, MA: Allyn and Bacon. McCutchen Publishing Corporation.

[3] Bloom, B.S. (1956). Taxonomy of educational objectives: The classification of educational goals. London. Longman.

[4] Brophy, J. (2001). Generic Aspects of Effective Teaching. Tomorrow's Teachers. Ed. Margaret C, Wang and Herbert J., Walberg., Richmond, C.A.

[5] Creswell, J. (2018). The Planning of Teaching in the Context of Lesson Study: Research Findings. International Education Studies. 11 (2), $67-82$.

[6] Eurydice-Maria, K., \& Maria, D. (2018). The planning of teaching in the context of lesson study: Research findings. International Education Studies 11 (2), 67-82.

[7] Giannakiodu, E. Rosati, K., \& Tziora, E. (2013). The reflective action at candidate teachers in applying and adapted version of the lesson study model. Hollenic Journal of Research in Education. $1,30-58$.

[8] Irfan, H., \& Shelina, B. (2016). Bloom's Taxonomy (cognitive Domain in Higher Education Settings: Reflection Brief. Journal of education and Educational Development. 3 (2), 288-300.

[9] Kolb, D. A. (2014). Experimental learning: Experience as the source of learning and development. New Jersey: Pearson Education, Inc.

[10] Krathwohl, D. R., \& Anderson, L. W. (2010). Wittrock and the revision of Bloom's Taxonomy. Educational Psychologist._45 (1), 64-65.

[11] Mwakamele, M. I. (2017). Using teachers' knowledge of Bloom's Taxonomy in determining the Quality of Classroom Assessment in Secondary Schools. Journal of Issues and Practice in Education. 9 (1) .

[12] Riazi, A. M., \& Mosalanejad, N. (2010). Evaluation of learning objectives in Iranian high school and pre-university English Textbooks using Bloom's taxonomy. ESL-EJ. The Electronic Journal for English as a Second Language. 13 (4). Retrieved from http://www.testej.org/wordpress/issues/volum13/ej52/ej52a5/ (0906-2020).

[13] Rupani, C. M. (2011). Evaluation of existing teaching learning process on Bloom's Taxonomy. International Journal of Academic Research in Business and Social Sciences. 1, 119-126.

[14] Sofos, A., \& Darra, M. (2015). Models of Learning Planning: Comparative and Interpretative Assessment. Education Science. 1, 66-83. 